\title{
Juvenile granulosa cell tumour in the third trimester of pregnancy
}

\author{
Jonathan Gaughran $^{1 *}$, Argha Datta ${ }^{2}$, Judith Hamilton ${ }^{1}$, Tom Holland ${ }^{1}$, Ahmad Sayasneh ${ }^{1,3}$
}

${ }^{1}$ Department Gynecology, Gynaecology Department. Guy's and St Thomas' Hospitals, London, United Kingdom

${ }^{2}$ Medical Student King's College London Medical School, London, United Kingdom

${ }^{3}$ School of Life Course Sciences, Faculty of Life Sciences and Medicine, King's College London, Guy's and St Thomas' Hospitals, London, United Kingdom

Received: 10 April 2019

Revised: 23 December 2019

Accepted: 27 December 2019

\section{*Correspondence:}

Mr. Jonathan Gaughran,

E-mail: jonathan.gaughran@gstt.nhs.uk

Copyright: ( ) the author(s), publisher and licensee Medip Academy. This is an open-access article distributed under the terms of the Creative Commons Attribution Non-Commercial License, which permits unrestricted non-commercial use, distribution, and reproduction in any medium, provided the original work is properly cited.

\section{ABSTRACT}

This case report describes the rare finding of a granulosa cell tumour in the third trimester of pregnancy. The presentation, investigation, management, histopathological findings and subsequent follow up are detailed. The difficulties associated with such diagnoses in pregnancy are explored.

Keywords: Cancer, Granulosa, Juvenile, Ovary, Ovarian, Pregnancy

\section{INTRODUCTION}

A granulosa cell tumour of the ovary (GCT) is a rare malignancy that arises from the sex-cord stromal cells. They account for $2-5 \%$ of ovarian cancers diagnosed worldwide. $^{1}$ The juvenile subtype, which occurs in premenerchal girls and younger women, is rarer still, accounting for $0.1 \%$ of all ovarian tumours. ${ }^{2}$ Juvenile GCTs most commonly present as a large pelvic mass and/or pubertal or menstrual irregularities due to the tumour secreting oestrogen, follicle-regulating protein, folliculin and inhibin. ${ }^{3}$ This case report described a case of Juvenile GCT detected incidentally during routine antenatal care.

\section{CASE REPORT}

A 26-year-old nulliparous lady attended a tertiary hospital in her first pregnancy for antenatal care. She had no significant medical or surgical history; BMI was 31 . Routine dating ultrasounds scan at 13 weeks gestation revealed an incidental fundal intramural fibroid measuring $88 \times 77 \times 61 \mathrm{~mm}$. Combined screening was low risk for chromosomal abnormalities. As per the local hospital protocol the ovaries were not assessed at 13 weeks.

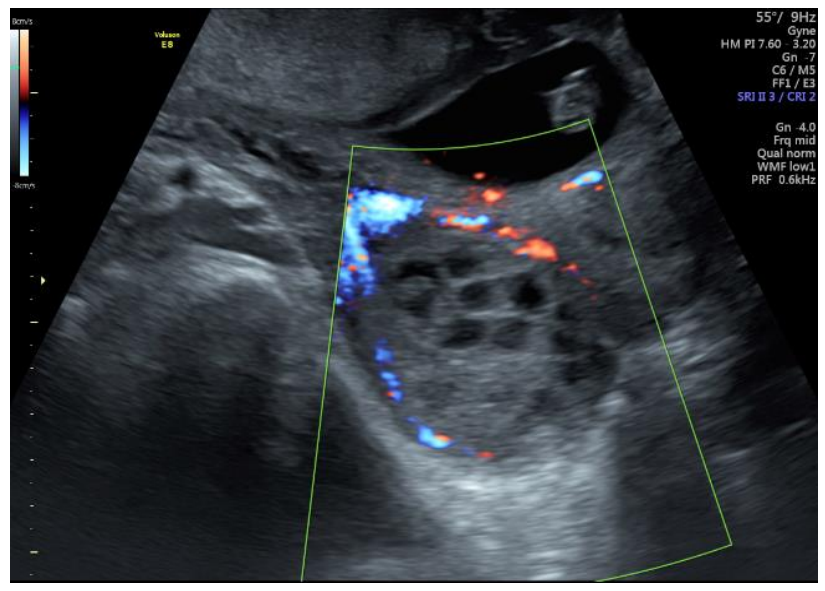

Figure 1: Trans-abdominal ultrasound transverse section of right ovary at 20 weeks gestation. Enlarged polycystic appearance with moderate peripheral doppler flow. 
The 20-week anomaly scan demonstrated an anatomically normal fetus measuring small for gestational age. The fibroid remained unchanged. The right ovary was noted to be enlarged measuring $85 \mathrm{cc}$ with a polycystic appearance and peripheral doppler flow (Figure 1).

Due to the abnormal appearance of the ovary and small fetus a plan was made for repeat growth scan at 24 weeks with re-assessment of the ovary. Unfortunately, the patient did not attend either the ultrasound scan nor follow up midwifery appointments, stating she had transferred care to another hospital. At 37 weeks the patient re-presented to the midwifery team having not had any interval care. An urgent ultrasound scan was arranged which demonstrated a footling breech with an estimated weight on the $5^{\text {th }}$ centile and normal dopplers. Within the right of the pouch of Douglas there was a large solid tumour measuring $139 \times 107 \times 105 \mathrm{~mm}$ containing cystic areas and moderate blood flow throughout (Figure 2 and 3). While the left ovary was normal, the right ovary could not be delineated and a working diagnosis was made of an ovarian non-epithelial malignant tumour, in particular low-grade stromal cell or germ cell tumours were suspected. The fibroid was unchanged.

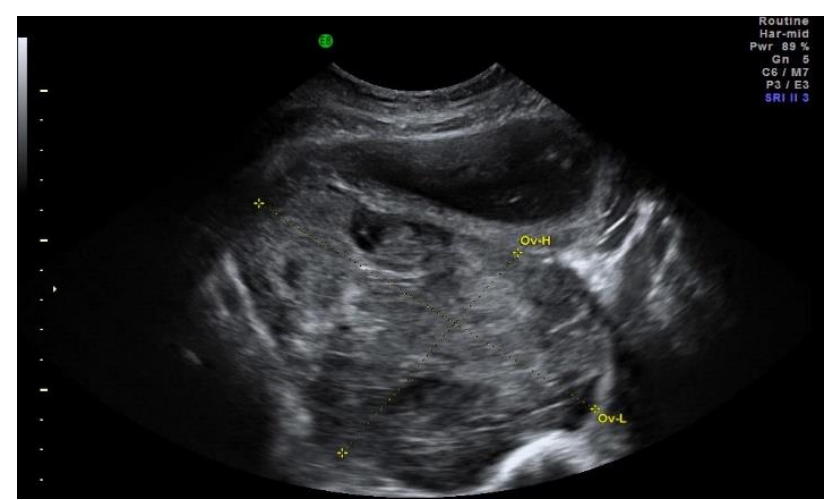

Figure 2: Trans-abdominal ultrasound parasagittal view of right adnexal mass with uterus sitting anterior. Solid mixed echogenicity with internal cystic areas.

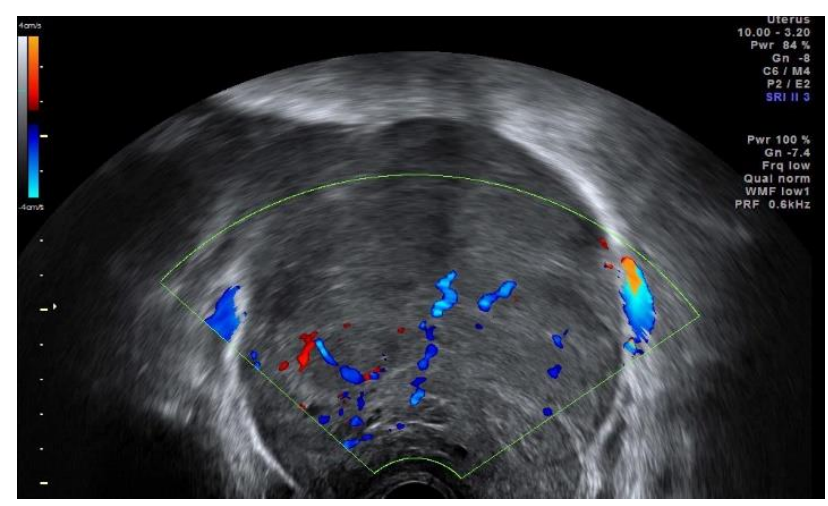

Figure 3: Transvaginal ultrasound transverse section of right ovarian mass demonstrating moderate doppler uptake in adnexal mass, colour score of 3.
A MRI without contrast was performed and reported as 'a complex mass in the region of the right adnexa, extending into the pouch of Douglas measuring $13 \times 7.5 \mathrm{~cm}$. This demonstrates heterogeneous signal intensity in keeping with haemorrhage. The lack of restricted diffusion within the intermediate T2-weighted signal components and overall appearances suggest a benign process, presumed acute, such as an ovarian torsion, however, the appearances were not typical' (Figure 4 and 5).

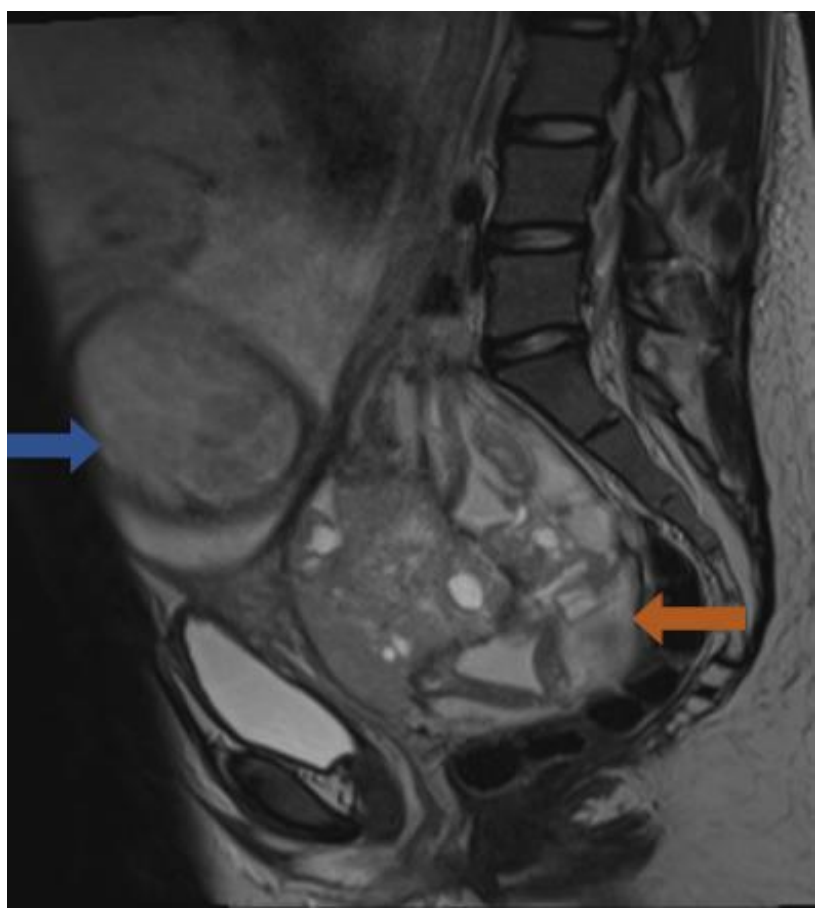

Figure 4: Non-contrast MRI Sagittal T2-weighted image demonstrating large, complex, mixed signal adnexal mass (red arrow) with gravis uterus (blue arrow).

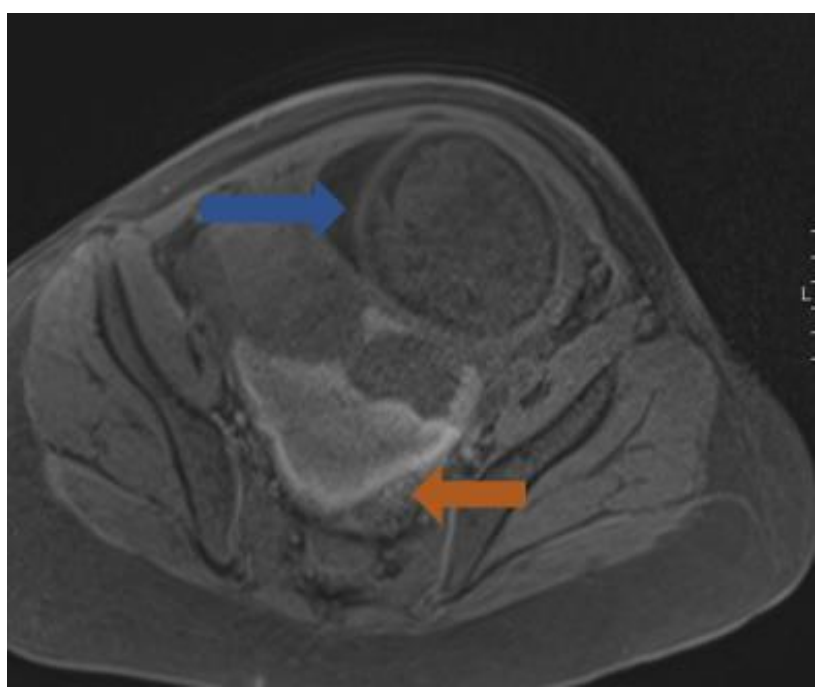

Figure 5: Non-contrast MRI axial T1W fat saturated image demonstrating high signal within mass in keeping with haemorrhage (red arrow) and gravis uterus (blue arrow). 
In view of the MRI (benign) and ultrasound (malignant) diagnostic discrepancy, the case was discussed in an obstetrics and gynaecology MDT and a decision made for elective caesarean section the following day with a unilateral salpingo-oopherectomy with omental and peritoneal biopsies and peritoneal washings to be performed by a gynaecology oncology surgeon.

Table 1: Pre-operative tumour markers.

\begin{tabular}{|lll|}
\hline $\begin{array}{l}\text { Tumour } \\
\text { marker }\end{array}$ & Result & $\begin{array}{l}\text { Normal reference } \\
\text { range }\end{array}$ \\
\hline Inhibin B & $3220 \mathrm{pg} / \mathrm{ml}$ & $0-341$ in pre-menopausal \\
\hline $\begin{array}{l}\text { Alpha feta } \\
\text { protein }\end{array}$ & $44.5 \mathrm{kIU} / \mathrm{L}$ & $0-5.8$ \\
\hline LDH & $307 \mathrm{U} / \mathrm{L}$ & $135-214$ \\
\hline CA-125 & $55 \mathrm{kU} / \mathrm{L}$ & $0-35$ \\
\hline CA-153 & $18 \mathrm{kU} / \mathrm{L}$ & $0-28$ \\
\hline
\end{tabular}

A live fetus was delivered without complication via midline laparotomy. The right ovary was grossly enlarged by a complex mass which was adherent to the posterior uterine wall. The left ovary and abdominopelvic cavity were otherwise unremarkable. An uncomplicated right salpingo-oppherectomy, omental biopsy, uterine serosa biopsy and peritoneal washing was performed and sent for histology and cytology. The patient made a good recovery and was discharged four days later.

\section{Histopathology findings}

\section{Macroscopic}

The ovarian mass measured $790 \mathrm{~g}$ with a smooth and glistening surface. There were two defects from where it had been excised from the posterior uterine wall. The fallopian tube was adherent. On sectioning there was extensive infarction and haemorrhage in over a third of the mass volume. The viable areas had a lobulated/nodular, firm, pale and focally haemorrhagic cut surface (Figure 6).

\section{Microscopic}

The viable tumour areas were well demarcated and consisted of sheets of round and oval to mildly elongated cells with a mixture of moderate eosinophilic or clear vacuolated cytoplasm. The cells were arranged in sheets, but areas with a vague trabecular appearance were also seen, as well as occasional irregular spaces containing eosinophilic fluid. Normal mitotic figures were easily found. The nuclei had small eosinophilic nucleoli and finely granular chromatin. There were areas of oedema, haemorrhage and infarction. There was intervening oedema and fibrosis with normal residual ovarian stroma seen focally at the periphery of the mass, containing luteinised stromal cells (Figure 7 and 8). The uterine serosa adhesion site consisted of congested fibro-vascular tissue, granulation tissue and viable tumour cells but no capsular surface tumour breach seen. The omental biopsy and LP ligament biopsy were clear of neoplasia. Peritoneal washings were negative.

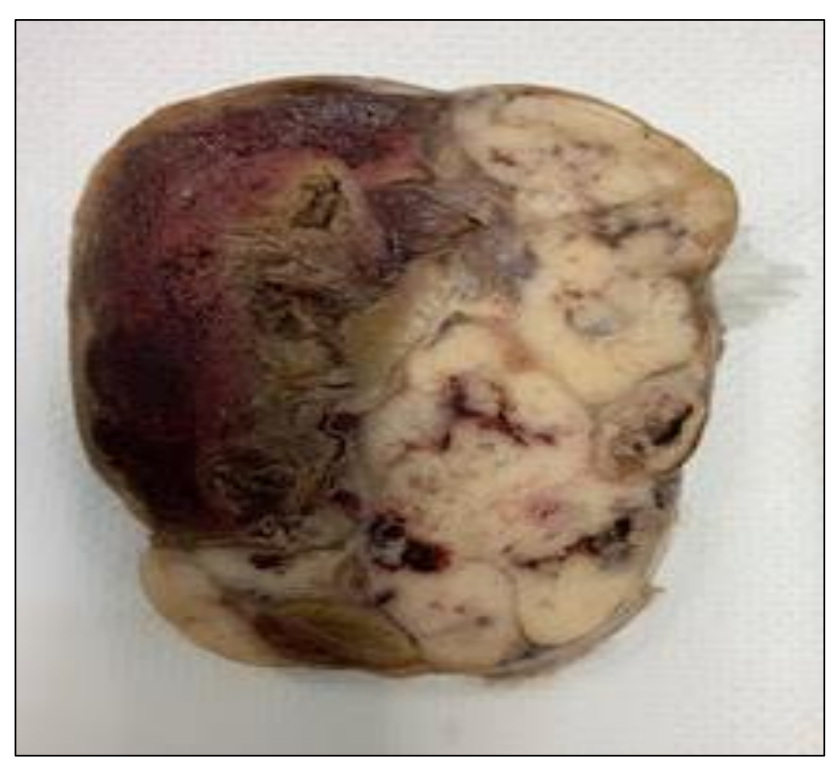

Figure 6: Macroscopic section of ovarian mass.

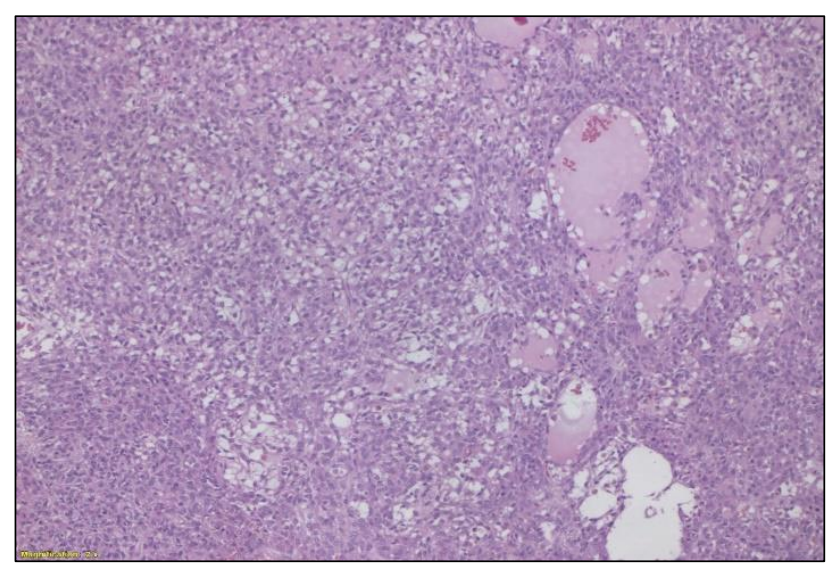

Figure 7: Low power magnification demonstrating solid areas with follicle-like spaces.

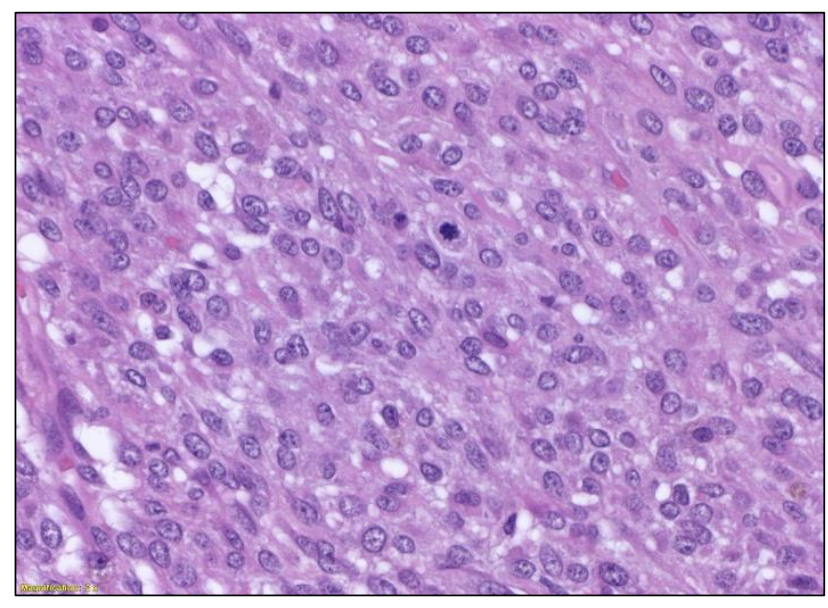

Figure 8: High power magnification of solid areas of tumour. 


\section{Immunohistochemistry}

There was diffuse positive staining for inhibin, CD56, pancytokeratins and SMA. Calretinin and S100 and MNF116 were focally positive. PAX8, WT1, GATA3, EMA and CD10 were negative.

\section{Expert opinion}

This case was deemed difficult to classify. Differentials included a pregnancy luteoma, granulosa cell tumour and Sertoli-Leydig cell tumour. An expert opinion was sought from Professor Glenn McCluggage at Queens University Belfast. In his opinion the overall architecture and presence of intermediate-size follicles favoured a juvenile granulosa cell tumour. Luteoma was considered less likely as they generally have a more epithelioid appearance and trabecular and nested areas unusual.

The case was discussed at the multi-disciplinary oncology meeting with an agreed diagnosis of stage $1 \mathrm{~A}$ juvenile granulosa cell tumour. A plan was made for a post-operative baseline CT abdomen and pelvis, with Inhibin B levels at 3 monthly intervals for the first year. At first follow up the patient had recovered well, Inhibin levels were normal at $<9.8 \mathrm{pg} / \mathrm{ml}$ and CT showed no sign of residual or disseminated disease. The patient will be followed up for 10 years.

\section{DISCUSSION}

Granulosa cell tumour is a rare malignancy, and its detection in pregnancy even more so. The incidence of ovarian carcinoma diagnosed during pregnancy varies between 0.0179 to 0.11 per 1000 pregnancies. 4 The physical changes associated with pregnancy, as well as unfamiliarity amongst ultrasound practitioners at assessing ovarian masses in pregnancy leads to diagnostic difficulties. The United Kingdom's foetal anomaly screening programme does not include assessment of the adnexa and sonographers performing these have varying degrees of expertise in gynaecology ultrasound. This case raises the question about the potential benefit of opportunistic screening of the adnexa during routine obstetric ultrasound. While a case like this would favour full assessment of the pelvis, evidence to date does not support screening for adnexal masses in the general population. ${ }^{5}$ When incidental adnexal masses are suspected, referral to an appropriately experienced clinician is recommended in order to avoid unnecessary intervention and the potential harm that can be caused.

Due to ionizing radiation associated with CT, MRI is the preferred imaging modality in pregnancy. However, movement artefact created by the fetus, contraindication of gadolinium uses in pregnancy, as well as the relatively recent use of MRI in pregnancy all decrease the diagnostic accuracy when compared to the non-pregnant state. ${ }^{6}$
Pregnancy also represents difficulties to the pathologist. In the case of GCTs studies have shown that during pregnancy there is a disorderly arrangement of tumour cells that result in the absence of recognizable differentiation in many areas as well as prominent oedema and large numbers of luteinized cells. These patterns are not frequently observed in juvenile GCTs of non-pregnant subjects. ${ }^{7}$

Conventional treatment is complete surgical staging via laparotomy. Lymphadenectomy, on the other hand, is not an essential part of staging, especially in young women. 8 Chemotherapy is considered for advanced stages but not for Stage IA. For younger patients wishing to preserve fertility, a staging laparotomy with unilateral salpingooophorectomy appears to be safe. ${ }^{6}$ Prognosis is dependent on tumour factors as well as staging, however in general it is excellent with many studies demonstrating five year survival rates of over $90 \%{ }^{8}$ While GCTs have low malignant potential and demonstrate slow growth, at least $50 \%$ of recurrences are found more than 5 years after initial treatment and therefore follow up is extended. ${ }^{6}$ Controversy exists over the benefit of definitive surgery following completion of family with no known evidence to support it in this case.

Due to the fact that the presentation was footling breach, the mode of delivery was to be caesarean section and so delivery was performed at the same time as staging surgery. However, in the case of a favorable foetal lie, patients should be counselled on the benefits and disadvantages of a vaginal birth followed by staging laparotomy. In this case the diagnosis was made in the $37^{\text {th }}$ week of pregnancy, however when diagnosed earlier in pregnancy the options of termination of pregnancy, or early delivery to facilitate timely treatment may need to be considered. This discussion should be made in collaboration with the obstetric and neonatal team balancing risk to mother and baby.

Funding: No funding sources

Conflict of interest: None declared

Ethical approval: Not required

\section{REFERENCES}

1. Ferlay J, Soerjomataram I, Dikshit R, Eser S, Mathers C. Cancer incidence and mortality worldwide: Sources, methods and major patterns in GLOBOCAN 2012. Int J Cancer. 2015;136:359-86.

2. Nikumbh D, Suryawanshi K, Chitale A, Pagare P, Surana A. Ovarian juvenile granulosa cell tumour in childhood: Uncommon gynecological malignancy. J Clin Diagn Res Doctors. 2014:8(10):1-2.

3. Gurumurthy M, Bryant A, Shanbhag S. Effectiveness of different treatment modalities for the management of adult-onset granulosa cell tumours of the ovary (primary and recurrent). Cochrane Database of Systematic Reviews. 2014;21:4. 
4. Xu H, Shu C, Li N, Meihui X, Li T. Early pregnancy complicated with juvenile granulosa cell tumour. Am J Med Sci. 2014;342(5):435-7.

5. Henderson JT, Webber EM, Sawaya GF. Screening for ovarian cancer: updated evidence report and systematic review for the US preventive services task force. JAMA. 2018;319(6):595-606.

6. Schumer S, Cannistra S. Granulosa cell tumor of the ovary. J Clin Oncol. 2003;21(6):1180-9.

7. Young R, Dudley A, Scully R. Granulosa cell, Sertoli-Leydig cell, and unclassified sex cord-stromal tumors associated with pregnancy: a clinicopathological analysis of thirty-six cases. Gynecol Oncol. 1984;18(2):181-205.

8. Mangili G, Ottolina J, Gadducci A, Giorda G, Breda E. Long-term follow-up is crucial after treatment for granulosa cell tumours of the ovary. $\mathrm{Br} \mathrm{J}$ Cancer. 2013;109(1):29-34.

Cite this article as: Gaughran J, Datta A, Hamilton J, Holland T, Sayasneh A. Juvenile granulosa cell tumour in the third trimester of pregnancy. Int $\mathbf{J}$ Reprod Contracept Obstet Gynecol 2020;9:861-5. 